\title{
Impact of Employment and Livelihood Programmes on Empowerment Level of the Beneficiaries
}

\author{
Khumukcham Stina ${ }^{*}$, L. Devarani ${ }^{2}$, R. J. Singh ${ }^{2}$, Ram $\operatorname{Singh}^{3}$ and L. Hemochandra ${ }^{4}$ \\ ${ }^{1}$ Multi Technology Testing Centre and Vocational Training Centre, College of Agriculture, \\ ${ }^{2}$ Department of Agricultural Extension, School of Social Sciences, College of Post Graduate \\ Studies in Agricultural Sciences, ${ }^{3}$ Department of Agricultural Economics, School of Social \\ Sciences, College of Post Graduate Studies in Agricultural Sciences, ${ }^{4}$ Department of \\ Agricultural Statistics, School of Social Sciences, College of Post Graduate Studies in \\ Agricultural Sciences, Central Agricultural University (Imphal), Umiam, Meghalaya, India
}

\section{Keywords}

MGNREGA, SGSY, empowerment, livelihood

\section{Article Info}

Accepted:

08 June 2020

Available Online:

10 July 2020
In contextual to large public expenditure for alleviation of poverty through generation of employment under Mahatma Gandhi National Rural Employment Guarantee Act (MGNREGA) and Swarnajayanti Gram Swarozgra Yojana (SGSY) in particular, the study try to take a stock as to how those flagship programmes impact on the empowerment level of the people apart from generating employment and livelihood. The study was conducted in Imphal East and Churachandpur districts of Manipur. A total of 185 respondents were interviewed to assess the impact on empowerment level of the respondents. 50 respondents each from beneficiaries of MGNREGA, beneficiaries of SGSY, beneficiaries of both (MGNREGA \& SGSY) and 35 non beneficiaries respondents were selected based on probability proportionate to size sampling, thus, forming a sample size of 185 respondents. The study reveals that after working under employment and livelihood linked programmes a positive impact could be observed on empowerment level of the beneficiaries of employment and livelihood linked programmes (MGNREGA \& SGSY). A significant difference among the four groups (beneficiaries of MGNREGA, beneficiaries of SGSY, beneficiaries of both MGNREGA \& SGSY and non-beneficiaries) in terms of empowerment was also observed; with highest (56.00) mean score obtained by SGSY beneficiaries.

\section{Introduction}

Even as India continues to record impressive growth rates, poverty remains widespread and disparities deeply entrenched. Poverty imposes an oppressive weight on India, especially in the rural areas where almost three out of four Indians and 77 percent of the Indian poor live. According to the UNDP [1] Global Human Development Report, India is ranked 134 in poverty out of 187 countries and UN-recognized territories. In India, chronic poorness is due to sustained experiencing of significant capability 
deprivations and thus the poor often pass on their poverty to subsequent generations, Hulme and Shepherd (3) .The state wise poverty estimates of 2011-12 as released by the Planning Commission, 2013 (2) was indicative that Manipur was one of the highest ranked states in India in terms of poverty ratio with a total of 240593 below poverty line households.

The major reason for poverty is unemployment. In India unemployment is mainly due to the shortage of capital, the poor exploitation of natural resources and inadequate employment opportunities. In view of these scenarios of unending rural poverty and unemployment in India since Independence, poverty eradication has been one of the most important objectives since the beginning of economic planning in India. It was realized that a sustainable strategy of poverty alleviation has to be based on increasing the productive employment opportunities in the process of growth itself.

Thus, it was necessary to formulate specific poverty alleviation programmes for generation of a certain minimum level of income for the rural poor. As a result, SGSY (self-employment programme) and MGNREGA (wage employment programme) came into being, which were found to be linked with livelihood and employment generation, with the main objective of improving the economic and social conditions of the rural poor by providing wage and selfemployment.

Now, contextual to large public expenditure for alleviation of poverty through generation of employment under Mahatma Gandhi National Rural Employment Guarantee Act (MGNREGA) and Swarnajayanti Gram Swarozgra Yojana (SGSY) in particular, the present researcher take a stock as to how those flagship employment and livelihood linked programmes in reality, been able to impact the empowerment level of the beneficiaries apart from the promises made during their introduction in respect to enhancement of the quality of life amongst the poverty stricken rural gentry, the study was initiated with the broad objective:

To assess the impact of the employment and livelihood linked programmes on empowerment level of the beneficiaries in Manipur.

\section{Materials and Methods}

The present study was conducted in the state of Manipur with the aim of assessing the impact of the livelihood and employment linked programmes viz., Mahatma Gandhi National Rural Employment Guarantee Act (MGNREGA) and Swarnajayanti Gram Swarozgar Yojana (SGSY), on empowerment level of the beneficiaries. Ex post facto research design was adopted for conducting the study. The state wise poverty estimates of 2011-12 as released by the Planning Commission, 2013 [2] was indicative that Manipur was one of the highest ranked states in India in terms of poverty ratio. One valley and one hill district of the state viz. Imphal East and Churachandpur respectively were selected purposively based on their relative better performance level in terms of the two employment and livelihood linked flagship programmes MGNREGA and SGSY. Probability proportionate to size sampling method was used to select the respondents from the constituent villages based on the following manner:

Step 1: Collection of current lists of below poverty line families from the selected villages

Step 2: Identification of job card holders under MGNREGA and members of self help 
groups (SHGs) under SGSY from the so collected lists of BPL families.

Step 3: Preparation of following four separate sub groups for each of the selected villages

\section{Group 1: Beneficiaries of MGNREGA}

\section{Group 2: Beneficiaries of SGSY}

Group 3: Beneficiaries of both MGNREGA and SGSY

Group 4: Non beneficiaries of MGNREGA and SGSY

Step 4: Selection of 50 respondents each from the first three groups and 35 respondents from the fourth group for all selected villages based on probability proportionate to size sampling, thus, forming a sample size of 185 respondents.

It was taken into consideration that all the beneficiary respondents belonging to the first three groups have become beneficiary 5 years prior to the time of data collection i.e., before 2009. Details of the sampling are presented in table 1 .

Further, the beneficiaries and nonbeneficiaries of the livelihood and employment linked programmes were interviewed personally to collect precise and comprehensive information on the impact. In order to measure the empowerment level of the respondents, index developed by Roy and Singh [5] comprising of 5 components viz. social participation, level of aspiration, selfconfidence, self-reliance and self-esteem was used. Hence, the empowerment index for each respondent was calculated with the following formula.

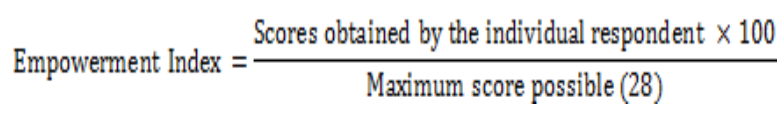

Categorization of the respondents was done as follows:

\begin{tabular}{|l|l|l|}
\hline SI. no. & $\begin{array}{l}\text { Empowerment } \\
\text { category }\end{array}$ & Scores obtained \\
\hline $\mathbf{1}$ & Very low & $0-20$ \\
\hline $\mathbf{2}$ & Low & $20-40$ \\
\hline $\mathbf{3}$ & Medium & $40-60$ \\
\hline $\mathbf{4}$ & High & $60-80$ \\
\hline $\mathbf{5}$ & Very high & $80-100$ \\
\hline
\end{tabular}

Analyses and interpretation of collected data were done by using the following statistical tools.

\section{T-test}

T- test is used for comparing the means of two independent groups. $t$ value is calculated by using the following formula.

$\mathrm{t}=\frac{\overline{\mathrm{x}}_{1}-\overline{\mathrm{x}}_{2}}{\sqrt[8]{\frac{1}{\mathrm{n}_{1}}+\frac{1}{\mathrm{n}_{2}}}}$ at $\mathrm{n}_{1}+\mathrm{n}_{2}-2 \mathrm{df}$

Where,

$\bar{x}_{1=}$ mean of first sample

$\overline{\mathrm{x}}_{2}=$ mean of second sample

$\mathrm{n}_{1}=$ number of observations in first sample

$\mathrm{n}_{2}=$ number of observations in second sample

$\mathrm{S}^{2}=$ the pooled mean square from the two samples

Independent sample t-test were used in many instances but if there was any kind of correspondence between the individual values in the two samples, they were paired and differences taken and analysed through paired t-test using the formula

$$
\mathrm{t}=\frac{d}{s(d)} \text { with } n-1 d f
$$

where, ${ }^{\bar{d}}=$ mean of the differences in each pair

$\mathrm{n}=$ pairs of observations

$s(\bar{d})=$ standard error of $^{\bar{d}}$ 


\section{Analysis of variance (ANOVA)}

ANOVA was done to find out whether the variation due to different treatments is significant in comparison with variation due to undistinguishing causes termed error variance. $F$ test provides an overall test of several differences with the principle to compare the variability between the various groups with the sum of variability found within the groups.

$$
\mathrm{F}=\frac{\text { Between groups mean square }}{\text { within groups mean square }}
$$

\section{Results and Discussion}

As mentioned above empowerment level of the respondent's household was measured using an empowerment index which comprises of five components viz., social participation, level aspiration, selfconfidence, self-reliance and self-esteem.

Mean score obtained by the respondents on the components of empowerment index by the four different groups has been displayed in table 2. and figure 1. From the table it is evident that there was a change in the mean score for every components of empowerment level before and after MGNREGA, before and after SGSY, beneficiaries of both MGNREGA and SGSY and nonbeneficiaries.

Mean score obtained by the respondents on the components of empowerment index before and after MGNREGA were displayed in table 2. The mean score presented revealed that after MGNREGA there was a major change in level of aspiration followed by self-confidence and social participation. This was in line with the findings of Roy and Singh [5]. It could also be observed that among the components, level of aspiration was found to have maximum changes after MGNREGA.
The probable reason might be after commencement of MGNREGA, the beneficiaries were getting employment opportunities under the programme. Though the average days of employment per household in the study area were only 8 days, but the respondents perceived that their purchasing power had been increased at least to a few degrees after working under MGNREGA. Road maintenance, renovation of water bodies, land development, mitigation of flood to some extent by constructing drain etc also contributes to their aspiration level. Bebarta [4] in his study also found that apart from providing employment, it ensures the livelihood security by creating durable assets.

The data in table also displayed the mean score obtained by the components of empowerment index before and after SGSY. The mean score obtained under before and after SGSY revealed that a maximum change was in level of aspiration, followed by social participation and self-esteem. The highest degree of change in level of aspiration among the various components of empowerment index may be due to full employment and unfailing monthly income from the SHGs in which they are the member. Likewise, significant increase in the income level was also reported by Das [8] and full employment after availing of the SGSY loan was also found by Sivachithappa [6].

Likewise, the mean score of beneficiary of both as well as non-beneficiary could also be noticed from the table portrayed. The result discerned that there were noticeable differences in the mean scores of all the components of empowerment index. Among which social participation acquired the highest difference in mean score, followed by level of aspiration and self-confidence. The utmost differences in the mean score of social participation indicates that, respondents under the category beneficiary of both, become 
more socialise as they became the member of various organisation as compared to nonbeneficiaries. Accordingly, frequency of knowing one another and active participation in various gathering increases since they were engaged in both the programmes.

From the result displayed in the table 2 it is evident that, changes had occurred in the mean scores of social participation, level of aspiration, self-confidence, self-reliance and self-esteem of the respondents before and after MGNREGA and before and after SGSY. An effort was made to find out whether the changes in the mean scores of the above mentioned components were statistically significant or not, and for that paired t-test was applied. The results of the paired t-test are displayed in the table 3 and 4.

From the result of the paired t-test it was found that, changes in the mean scores of all the components of empowerment index before and after MGNREGA were statistically significant. The changes in the mean score of social participation, level of aspiration, self-confidence, self-reliance and self-esteem were statistically significant at one percent level of significance as the calculated t-value of the above said components were more than the table value.

Similarly, yet again from the result of the paired t-test it was found that, changes in the mean scores of all the components of empowerment index for before and after SGSY were statistically significant. The changes in the mean score of social participation, level of aspiration, selfconfidence, self-reliance and self-esteem were statistically significant at one percent level of significance as the calculated t-value of the above said components were more than the table value. Again an attempt was made to assess the impact of employment and livelihood linked programmes on the empowerment of the beneficiaries. Table 5 shows the distribution of respondents on the empowerment level before and after MGNREGA, before and after SGSY, beneficiary of both and non-beneficiary. The result revealed drastic changes on empowerment of the respondents before and after MGNREGA. It was observed that majority $(62 \%)$ of the respondents were found to be fallen under low empowerment category before MGNREGA. But after working under MGNREGA, majority (94\%) of the respondents were found to be in medium category.

Impact assessment of SGSY on empowerment of respondents was also found out. The data in table exhibited the distribution of respondents on empowerment before and after SGSY. A study of the table reveals that majority of the respondents $(56 \%)$ were found to be under low empowerment category before SGSY. But after working under SGSY majority $(88 \%)$ of the respondents were found to be fallen under medium empowerment category. Thus, shows a positive impact on empowerment of the respondents. Likewise, Umdor and Panda [7] has also found that SGSY has empowered the members and their households both economically and socially.

From the table again, distribution of the respondents who were getting the benefits from both the programmes (MGNREGA and SGSY) i.e. "beneficiary of both" could be observed. Through the result displayed, it could be determined that majority of them $(66 \%)$ fall under medium category followed by high (22\%) and low (12\%).

Based on empowerment, distribution of respondents who were not getting any benefits from both the programmes (MGNREGA and SGSY) i.e. "nonbeneficiary" was also depicted in table 5.The data in shows that majority $(54.92 \%)$ of the 
respondents belonged to low category followed by (45.71\%) medium category. Low income, unemployment and almost no participation in social gatherings might have contributed to accumulation of majority of respondents in low empowerment category.

Overall the empowerment level of beneficiary of both was higher as though majority were in medium category but a (22\%) of the respondents were also found to be in high category followed by low which is only $(12 \%)$ of the respondents. Further, to be more precise, paired t-test and ANOVA was applied to find out whether the change in empowerment level of the respondents within the group as well as among the group was statistically significant or not. From the result of the paired t-test displayed in table 6 revealed that, the change in empowerment level of the respondents before after MGNREGA and before after SGSY were statistically significant at one percent level of significance. Similarly, the value of ANOVA portrayed in table also made known that, there was significant differences among the four groups in terms of empowerment level at one percent level of significance, revealing a positive changes of the programmes on the empowerment of the beneficiaries. The empowerment index of the SGSY beneficiaries was found to be highest (56.00) among the four groups.

Table.1 Selection of respondent households based on probability proportionate to size sampling

\begin{tabular}{|l|l|l|c|c|c|c|c|c|c|c|}
\hline \multirow{2}{*}{ Districts } & Villages & \multicolumn{4}{|c|}{ Total no. of households } & \multicolumn{3}{c|}{ No. of households selected } \\
\hline & & BPL & MGNREGA $^{\mathbf{1}}$ & SGSY $^{\mathbf{1}}$ & Both $^{\mathbf{2}}$ & N.B $^{\mathbf{3}}$ & MGNREGA $^{\mathbf{1}}$ & SGSY $^{\mathbf{1}}$ & Both $^{\mathbf{2}}$ & N.B $^{\mathbf{3}}$ \\
\hline $\begin{array}{l}\text { Imphal } \\
\text { East }\end{array}$ & Achanbigei & 305 & 219 & 26 & 43 & 17 & 9 & 16 & 15 & 7 \\
\hline & $\begin{array}{l}\text { Bamon } \\
\text { Kampu }\end{array}$ & 372 & 302 & 17 & 34 & 19 & 11 & 11 & 11 & 8 \\
\hline $\begin{array}{l}\text { Churacha } \\
\text { ndpur }\end{array}$ & $\begin{array}{l}\text { Hiangtam } \\
\text { Lamka }\end{array}$ & 564 & 472 & 22 & 38 & 32 & 17 & 14 & 13 & 12 \\
\hline & Bijang & 418 & 353 & 12 & 32 & 21 & 13 & 9 & 11 & 8 \\
\hline Total & $\mathbf{4}$ & & & & & & $\mathbf{5 0}$ & $\mathbf{5 0}$ & $\mathbf{5 0}$ & $\mathbf{3 5}$ \\
\hline
\end{tabular}

Note: 1. Beneficiaries of the respective programmes

2. Beneficiaries of both the programmes

3. Non beneficiaries

Table.2 Mean score obtained by the respondents on the components of empowerment index by the four different groups

\begin{tabular}{|l|l|l|l|l|l|l|}
\hline Particulars & $\begin{array}{l}\text { Before } \\
\text { MGNREGA }\end{array}$ & $\begin{array}{l}\text { After } \\
\text { MGNREGA }\end{array}$ & $\begin{array}{l}\text { Before } \\
\text { SGSY }\end{array}$ & $\begin{array}{l}\text { After } \\
\text { SGSY }\end{array}$ & $\begin{array}{l}\text { Beneficiary } \\
\text { of both the } \\
\text { programmes }\end{array}$ & $\begin{array}{l}\text { Non- } \\
\text { beneficiary }\end{array}$ \\
\hline $\begin{array}{l}\text { Social } \\
\text { participation }\end{array}$ & 2.48 & 3.20 & 2.52 & 3.58 & 4.42 & 2.63 \\
\hline Level aspiration & 3.62 & 4.42 & 3.50 & 4.72 & 4.26 & 3.86 \\
\hline Self confidence & 1.78 & 2.52 & 1.52 & 2.10 & 1.96 & 1.60 \\
\hline Self-reliance & 2.30 & 2.58 & 2.96 & 3.18 & 3.06 & 3.09 \\
\hline Self esteem & 1.30 & 1.72 & 1.44 & 2.10 & 1.78 & 1.46 \\
\hline
\end{tabular}


Table.3 Pair t-test value to test the significance of the mean difference of the components of empowerment before and after MGNREGA $(n=50)$

\begin{tabular}{|l|c|c|c|}
\hline Particulars & Before MGNREGA & After MGNREGA & t - value \\
\hline Social participation & 2.48 & 3.20 & $-5.62 * *$ \\
\hline Level aspiration & 3.62 & 4.42 & $-7.00 * *$ \\
\hline Self confidence & 1.78 & 2.52 & $-10.74 * *$ \\
\hline Self reliance & 2.30 & 2.58 & $-3.98 * *$ \\
\hline Self esteem & 1.30 & 1.72 & $-5.95 * *$ \\
\hline
\end{tabular}

**significant at 1 per cent level of significance

Table.4 Pair t-test value to test the significance of the mean difference of the components of empowerment before and after SGSY $(n=50)$

\begin{tabular}{|l|c|c|c|}
\hline Particulars & Before SGSY & After SGSY & t - value \\
\hline Social participation & 2.52 & 3.58 & $-9.45^{* *}$ \\
\hline Level aspiration & 3.50 & 4.72 & $-10.26 * *$ \\
\hline Self confidence & 1.52 & 2.10 & $-8.22^{* *}$ \\
\hline Self-reliance & 2.96 & 3.18 & $-3.71 * *$ \\
\hline Self esteem & 1.44 & 2.10 & $-9.75^{* *}$ \\
\hline
\end{tabular}

**significant at 1 per cent level of significance

Table.5 Distribution of the respondents according to their empowerment level

\begin{tabular}{|c|c|c|c|c|c|c|}
\hline \multirow[t]{2}{*}{ Categories } & \multicolumn{2}{|c|}{$\begin{array}{l}\text { MGNREGA } \\
\text { beneficiaries }\end{array}$} & \multicolumn{2}{|c|}{ SGSY beneficiaries } & \multirow{2}{*}{$\begin{array}{c}\text { Beneficiaries } \\
\text { of both the } \\
\text { programmes }\end{array}$} & \multirow[t]{2}{*}{$\begin{array}{c}\text { Non- } \\
\text { beneficiaries }\end{array}$} \\
\hline & Before & After & Before & After & & \\
\hline Very low $\quad(0-20)$ & - & - & - & - & - & - \\
\hline$(21-40)$ & $31(62.00)$ & $3(6.00)$ & $28(56.00)$ & $1(2.00)$ & $6(12.00)$ & $19(54.92)$ \\
\hline Medium (41-60) & $19(38.00)$ & $47(94.00)$ & $22(44.00)$ & $44(88.00)$ & $33(66.00)$ & $16(45.71)$ \\
\hline High $\quad(61-80)$ & - & - & - & $5(10.00)$ & $11(22.00)$ & - \\
\hline Very high (81-100) & - & - & - & - & - & - \\
\hline
\end{tabular}

Figure in parentheses indicates percentage to the total 
Table.6 Mean score of empowerment level obtained by different groups of respondents

\begin{tabular}{|c|c|c|c|c|c|c|}
\hline & \multicolumn{2}{|c|}{$\begin{array}{l}\text { MGNREGA beneficiaries } \\
\qquad(n=50)\end{array}$} & \multicolumn{2}{|c|}{$\begin{array}{c}\text { SGSY } \\
\text { beneficiaries } \\
(n=50)\end{array}$} & \multirow{2}{*}{$\begin{array}{c}\text { Beneficiaries } \\
\text { of both the } \\
\text { programmes } \\
(n=50)\end{array}$} & \multirow[t]{2}{*}{$\begin{array}{c}\text { Non } \\
\text { beneficiaries } \\
(\mathbf{n}=\mathbf{5 0})\end{array}$} \\
\hline & $\begin{array}{c}\text { Before } \\
\text { MGNREGA }\end{array}$ & $\begin{array}{c}\text { After } \\
\text { MGNREGA }\end{array}$ & $\begin{array}{l}\text { Before } \\
\text { SGSY }\end{array}$ & $\begin{array}{l}\text { After } \\
\text { SGSY }\end{array}$ & & \\
\hline $\begin{array}{l}\text { Total mean score of } \\
\text { empowerment level }\end{array}$ & 41.00 & 51.57 & 42.64 & 56.00 & 55.29 & 45.10 \\
\hline Paired t- test & \multicolumn{2}{|c|}{$-13.377 * *$} & \multicolumn{2}{|c|}{$-14.839 * *$} & & \\
\hline $\begin{array}{l}\text { ANOVA for total mean } \\
\text { score }(F)\end{array}$ & \multicolumn{6}{|c|}{$18.081 * *$} \\
\hline
\end{tabular}

**significant at 1 per cent level of significance

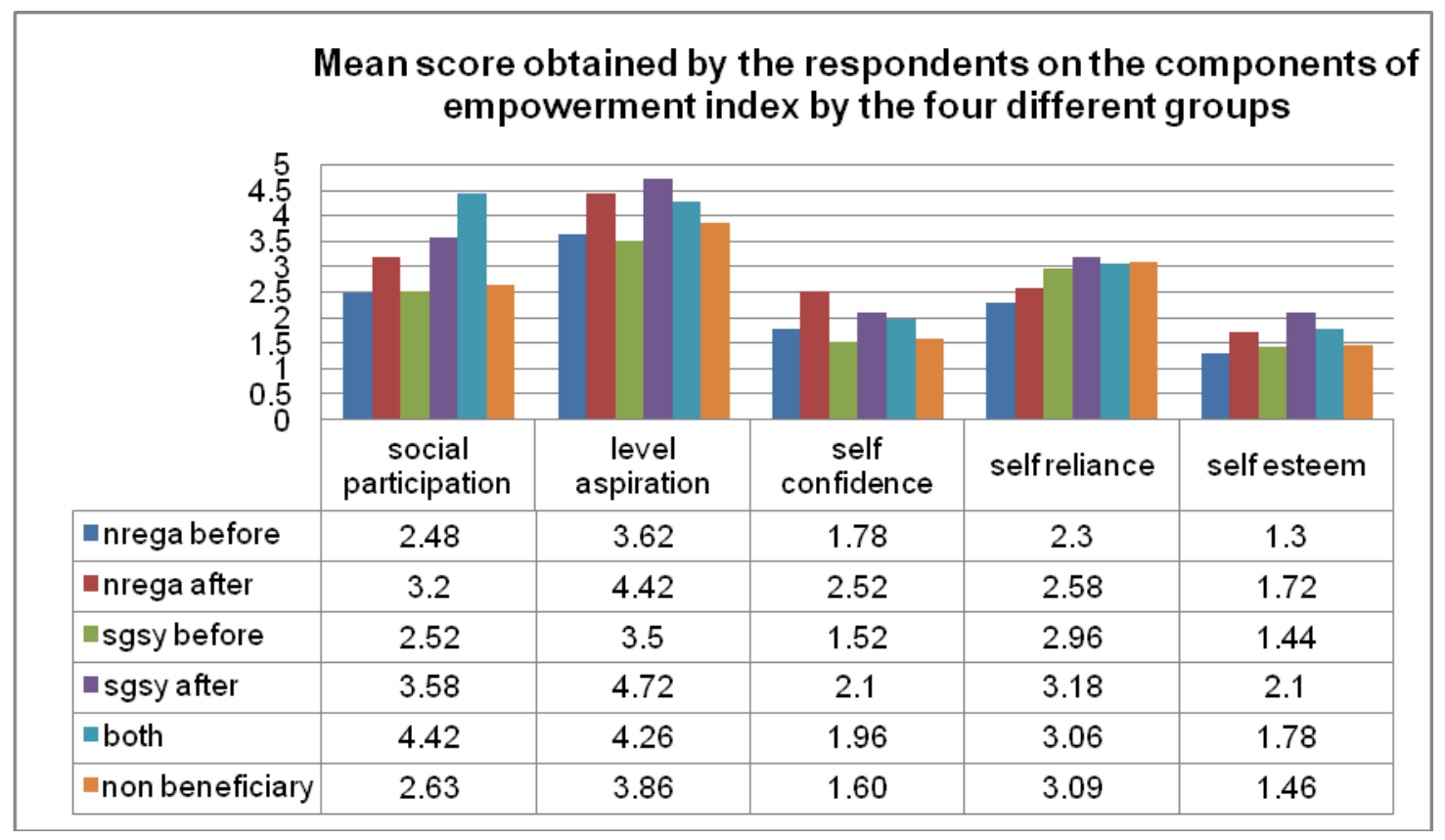

Figure.1 Mean score obtained by the respondents on the components of empowerment index by the four different groups

After working under employment and livelihood linked programmes, majority of the respondents found in the category low empowerment were observed to be uplifted to medium level of empowerment. While majority of the respondents under the group non beneficiaries were found to be in low empowerment category. A significant difference among the four groups in terms of empowerment was also observed; with highest (56.00) mean score obtained by SGSY beneficiaries. Thus, a positive impact could be observed on empowerment level of the beneficiaries of employment and livelihood linked programmes.

\section{References}

Bebarta, P.K. 2013. Impact of MGNREGA in the lives of tribal people: A study of Rayagada Block in Gajapati District. Odisha Rev. (Feb. - Mar.).

Das, B.C. 2013. Economic Development of SHG Members Financed by Regional Rural Banks under Swarnajayanti Gram Swarojgar Yojana. Indian Res. 
J. Ext. Edu.; 13 (1): 107-111.

Hulme, D., Shepherd, A. 2003. Conceptualizing Chronic Poverty. World Develop. 31:403- 423.

Planning Commission, Government of India. 2013. Press Note on Poverty Estimates, 2011- 12, GoI, New Delhi..

Roy, S., and Singh, B. 2010. Impact of NREGA on Empowerment of the Beneficiaries in West Bengal. Indian Res. J. Ext. Edu. 10(2): 21-24.

Sivachithappa, K. 2012. The Impact of Swarnajayanti Gram Swarozgar Yojana on Poverty Alleviation - A
Case Study of Tumkur District. Asian J. Res. in Bus. Econ. Manage. 2(7): 202-219.

Umdor, S., Panda, S. 2009. An Assessment of SHGs under SGSY Programme: Evidence from Meghalaya. Asian Econ. Rev. 51(2):311-325.

UNDP. 2011. Poverty Reduction and Livelihoods Promotion. Accessed 27 July 2014. Available:http://www.in.undp.org/cont ent/india/en/home/ourwork/povertyred uction/overview

\section{How to cite this article:}

Khumukcham Stina, L. Devarani, R. J. Singh, Ram Singh and Hemochandra. L. 2020. Impact of Employment and Livelihood Programmes on Empowerment Level of the Beneficiaries. Int.J.Curr.Microbiol.App.Sci. 9(07): 800-808. doi: https://doi.org/10.20546/ijcmas.2020.907.092 